\title{
Editorial
}

\section{Glucagon-Like Peptide-1 and Diabetes}

\author{
Matteo Monami \\ Geriatric Medicine and Cardiology, Diabetes Section, Careggi Teaching Hospital, 50141 Florence, Italy \\ Correspondence should be addressed to Matteo Monami, mmonami@libero.it
}

Received 25 October 2011; Accepted 25 October 2011

Copyright (c) 2011 Matteo Monami. This is an open access article distributed under the Creative Commons Attribution License, which permits unrestricted use, distribution, and reproduction in any medium, provided the original work is properly cited.

This special issue was focused on the role and the effects of glucagon-like peptide-1 (GLP-1) in type 2 diabetes. This gastrointestinal hormone, which is mainly secreted after meals, enhances glucose-stimulated insulin release and inhibits food intake. The response of circulating active GLP-1 concentrations after a standard meal, as well as after an oral glucose load, has been reported to be reduced in type 2 diabetic patients in comparison with healthy subjects. Available data suggest that GLP-1 plays a relevant role in the regulation of postprandial glucose metabolism in physiologic conditions. Furthermore, the impairment of GLP-1 secretion after meals could contribute to the pathogenesis of hyperglycemia in type 2 diabetes. Several new drugs act through the GLP-1 signaling system to stimulate insulin release and regulate blood glucose levels in patients with diabetes.

This special issue includes 8 articles: three mechanistic studies and five reviews and meta-analyses, exploring the putative favourable effects of the incretins on beta-cell function and mass and on gastrointestinal motor function. The reviews and meta-analyses are focused on the promising beneficial extraglycaemic effects of the incretin-based therapy, including those on central nervous system (cognitive impairment) and cardiovascular risk. Last but not least, an interesting and intriguing review on gene therapy using expression vectors of GLP-1 and other incretin mimetics in the salivary gland for the treatment of type 2 diabetes mellitus (T2 DM) is presented. 


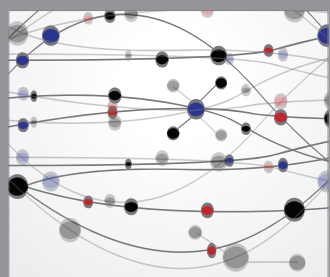

The Scientific World Journal
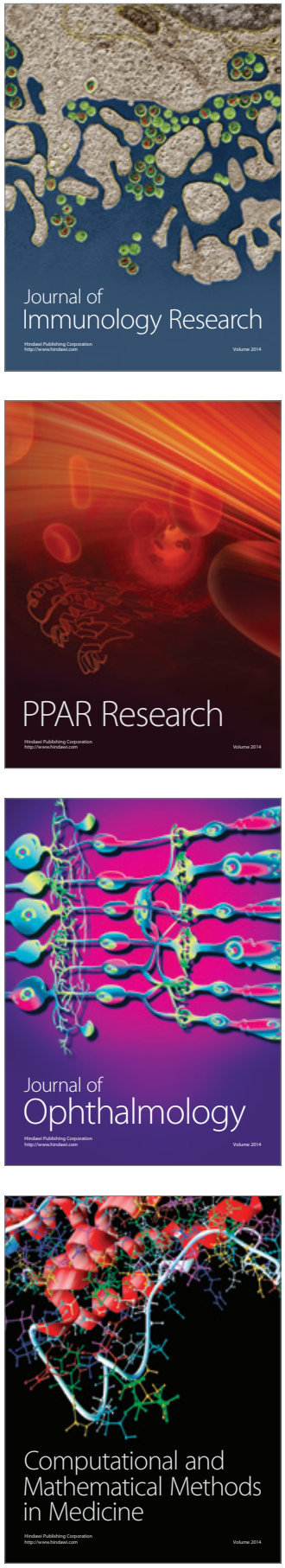

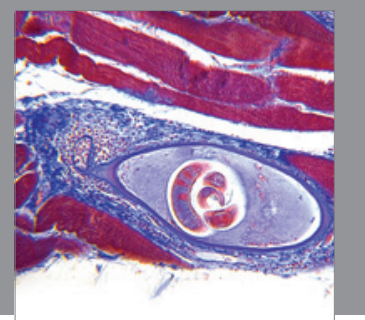

Gastroenterology

Research and Practice
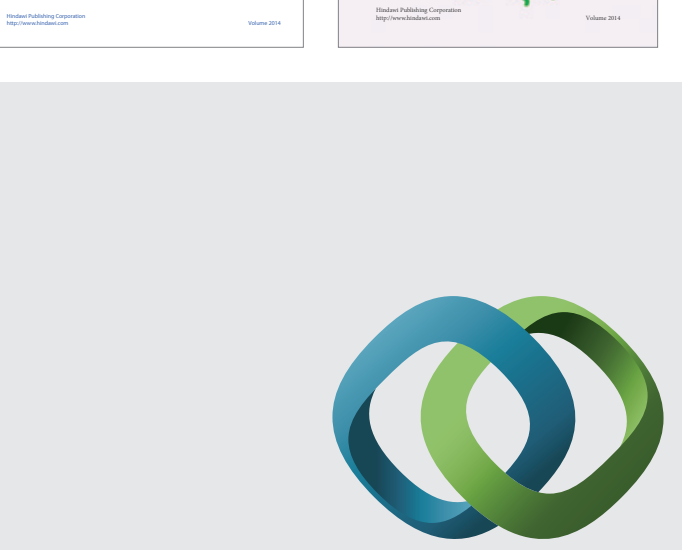

\section{Hindawi}

Submit your manuscripts at

http://www.hindawi.com
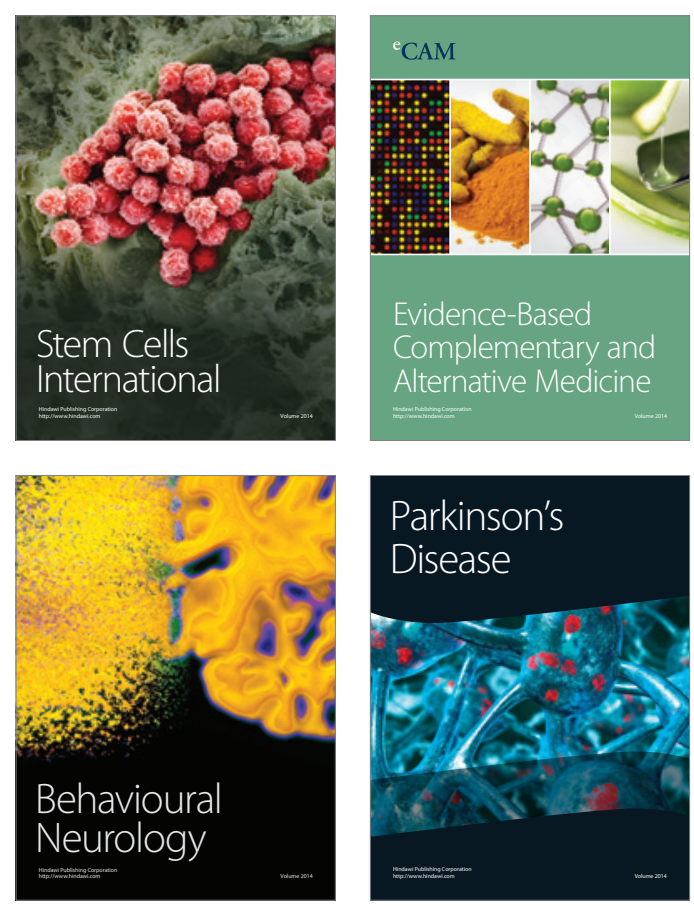

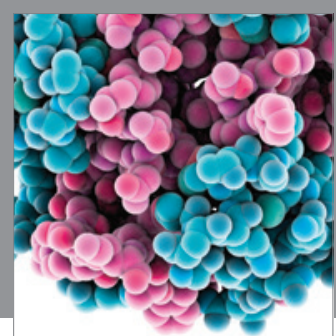

Journal of
Diabetes Research

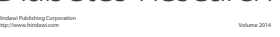

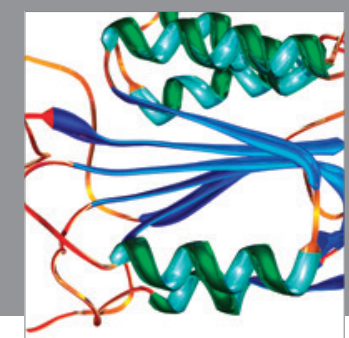

Disease Markers
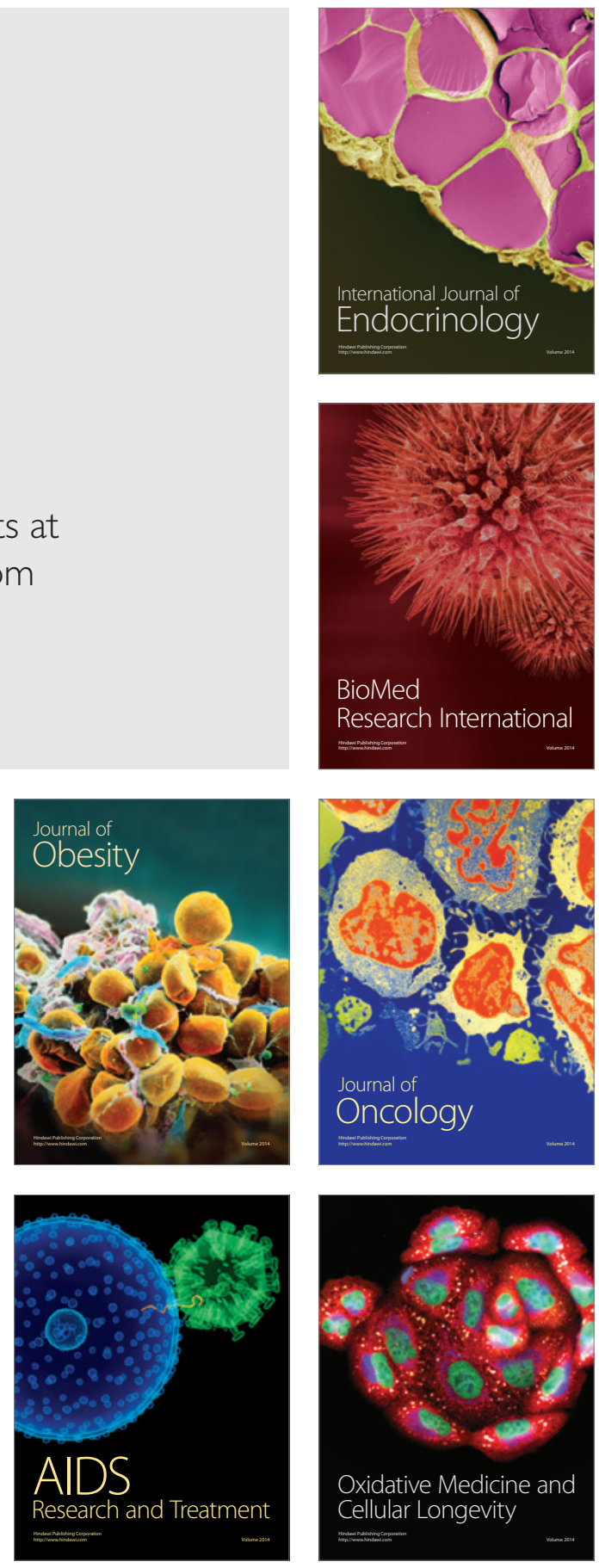